Case Report

\title{
Durable Red Blood Cell Transfusion Independence in a Patient with an MDS/MPN Overlap Syndrome Following Discontinuation of Iron Chelation Therapy
}

\author{
Harpreet Kochhar, ${ }^{1}$ Chantal S. Leger, ${ }^{2}$ and Heather A. Leitch ${ }^{2}$ \\ ${ }^{1}$ Department of Medicine, University of St. Eustatius, Tucker, GA 30084, USA \\ ${ }^{2}$ Division of Hematology, St. Paul's Hospital, University of British Columbia, Vancouver, BC, Canada V6Z $2 A 5$ \\ Correspondence should be addressed to Heather A. Leitch; hleitch@providencehematology.com
}

Received 25 November 2014; Revised 11 January 2015; Accepted 6 March 2015

Academic Editor: Sudhir Tauro

Copyright ( 2015 Harpreet Kochhar et al. This is an open access article distributed under the Creative Commons Attribution License, which permits unrestricted use, distribution, and reproduction in any medium, provided the original work is properly cited.

\begin{abstract}
Background. Hematologic improvement (HI) occurs in some patients with acquired anemias and transfusional iron overload receiving iron chelation therapy (ICT) but there is little information on transfusion status after stopping chelation. Case Report. A patient with low IPSS risk RARS-T evolved to myelofibrosis developed a regular red blood cell (RBC) transfusion requirement. There was no response to a six-month course of study medication or to erythropoietin for three months. At 27 months of transfusion dependence, she started deferasirox and within 6 weeks became RBC transfusion independent, with the hemoglobin normalizing by 10 weeks of chelation. After 12 months of chelation, deferasirox was stopped; she remains RBC transfusion independent with a normal hemoglobin 17 months later. We report the patient's course in detail and review the literature on HI with chelation. Discussion. There are reports of transfusion independence with ICT, but that transfusion independence may be sustained long term after stopping chelation deserves emphasis. This observation suggests that reduction of iron overload may have a lasting favorable effect on bone marrow failure in at least some patients with acquired anemias.
\end{abstract}

\section{Introduction}

The myelodysplastic syndromes (MDS) are a heterogeneous group of clonal hematopoietic stem cell disorders characterized by ineffective blood cell production and a propensity to progress to acute myelogenous leukemia (AML). Survival and AML risk are predicted by the International Prognostic Scoring System (IPSS) and other prognostic scores [1-5]. Anemia is a common manifestation of MDS and most patients eventually become red blood cell (RBC) transfusion dependent (TD), which can have a significant adverse impact on quality of life [6]. Transfusion dependence in MDS has been associated with inferior overall survival (OS) and leukemia free survival (LFS), as has iron overload as measured by serum ferritin (SF) level [7-12]. Several analyses suggest that patients with lower risk MDS who received iron chelation therapy (ICT) had improved OS and possibly LFS compared to those who did not [13-21]. Some analyses suggest that the degree of survival benefit is associated with a longer period of chelation or with more effective reduction in SF $[15,20]$. Similar data in smaller numbers suggest that patients with myeloproliferative neoplasms (MPN) and transfusional iron overload may also have inferior survival $[22,23]$ and might experience a survival benefit with chelation [24].

There are reports of hematologic improvement (HI) [25, 26] in a proportion of MDS [27-37] and MPN [38-44] patients receiving chelation, with some patients achieving transfusion independence (TI); however, information on transfusion status after stopping chelation is minimal and has received little attention to date. We report a 63-yearold woman with IPSS low risk refractory anemia with ring sideroblasts and thrombocytosis (RARS-T) who progressed to transfusion dependent myelofibrosis. Six weeks following the initiation of ICT, she became transfusion independent. When ICT was discontinued due to lack of financial coverage, 
the hemoglobin remained normal with ongoing transfusion independence seventeen months later.

This paper was written in accordance with the requirements of the Providence Research Institute Research Ethics Board.

\section{Case Report}

A 63-year-old woman was referred in October 2009 for a tenmonth history of macrocytic anemia and thrombocytosis. She was otherwise asymptomatic. Physical examination was unremarkable. Blood work showed a white blood cell count of $11.5 \times 10^{9} / \mathrm{L}$, hemoglobin $(\mathrm{Hb}) 109 \mathrm{~g} / \mathrm{L}, \mathrm{MCV} 110 \mathrm{fL}$, platelets (PLT) $1,384 \times 10^{9} / \mathrm{L}$, neutrophils $6.3 \times 10^{9} / \mathrm{L}$, and SF of $223 \mathrm{ng} / \mathrm{mL}$. Peripheral blood morphology showed thrombocytosis with large platelet forms. A bone marrow aspirate and biopsy showed RARS-T, an MDS/MPN-unclassifiable in the World Health Organization (WHO) provisional category [46]. Cytogenetic analysis showed a normal female karyotype and she was IPSS for MDS low risk with a predicted median survival of 5.7 years. Analysis for both JAK-2 (V617F) and BCR-ABL were negative.

In February 2010 she was started on cytoreduction with hydroxyurea because of thrombocytosis (Hb was $97 \mathrm{~g} / \mathrm{L}$ and PLT count was $2,497 \times 10^{9} / \mathrm{L}$ ) associated with pseudohyperkalemia. In April 2010 she presented with fatigue; at that time the $\mathrm{Hb}$ was $76 \mathrm{~g} / \mathrm{L}$ and the PLT count was $1,976 \times 10^{9} / \mathrm{L}$. In May 2010 the patient was started on RBC transfusions. By October 2010 the transfusion requirement (TR) was 2-unit (U) RBC every four weeks and the SF was $318 \mathrm{ng} / \mathrm{mL}$ with a transferrin saturation of $67 \%$. There was no clinical bleeding throughout the patient's course. To rule out occult blood loss, the patient underwent CT colonography in November 2010, which was negative for any colonic lesions.

In March 2011 a leukoerythroblastic picture was noted on the blood smear. A repeat bone marrow biopsy showed clusters of megakaryocytes, myeloid proliferation, grade 3 reticulin fibrosis, and reduced erythropoiesis; the SF was $960 \mathrm{ng} / \mathrm{mL}$. A diagnosis of myelofibrosis (MF) was made. Analysis for the JAK-2 V617F mutation remained negative. The Dynamic International Prognostic Scoring System-Plus (DIPSS+) score for primary myelofibrosis was 3, predicting a median OS of 35 months and $12 \%$ risk of progression to AML at ten years [47]. According to the MDS/fibrosis score [48] the projected median OS was 24 months with a three-year AML risk of $40 \%$.

In May 2011, the SF was $1066 \mathrm{ng} / \mathrm{mL}$. The DIPSS+/SF score at the onset of a $\mathrm{SF} \geq 1000$ predicts a median OS of 34 months [23]. She was assessed for a clinical trial of pomalidomide (versus placebo) and enrolled on the study in July 2011 after stopping cytoreduction. She was withdrawn from the study in January 2012 for lack of response and restarted hydroxyurea. The SF was $1970 \mathrm{ng} / \mathrm{mL}$. In February 2012, the RBC TR was 2.5 units per 4 weeks. Fecal occult bloods were done in April 2012, which were negative. EPO was initiated in May 2012 at a dose of 40,000 $\mathrm{U} /$ week. The pretransfusion $\mathrm{Hb}$ prior to starting EPO were $81 \mathrm{~g} / \mathrm{L}$ and six weeks later was $76 \mathrm{~g} / \mathrm{L}$.

Deferasirox (DFX) was started in June 2012 at a dose of $20 \mathrm{mg} / \mathrm{kg} / \mathrm{day}$ and the patient received a last transfusion on August 7, 2012, at which time the pretransfusion $\mathrm{Hb}$ was $101 \mathrm{~g} / \mathrm{L}$ and the SF was $1251 \mathrm{ng} / \mathrm{mL}$. Two months later, the $\mathrm{Hb}$ was 133 (lower limit of normal 120) g/L and the SF was $911 \mathrm{ng} / \mathrm{mL}$. At this point, the DIPSS+ score was low risk as she was transfusion independent, with a predicted median OS of 185 months [47]. The hydroxyurea dose was reduced as the PLT count was 237 (normal range $150-400) \times 10^{9} / \mathrm{L}$ and EPO was stopped in January 2013.

In May 2013, the $\mathrm{Hb}$ remained normal at $125 \mathrm{~g} / \mathrm{L}$ and the SF was $685 \mathrm{ng} / \mathrm{mL}$. Deferasirox was stopped as she no longer met BC Pharmacare criteria for coverage, as she was no longer transfusion dependent. The $\mathrm{Hb}$ was $140 \mathrm{~g} / \mathrm{L}$ and SF was $541 \mathrm{ng} / \mathrm{mL}$ in December 2013. In October 2014, 60 months from diagnosis of RARS-T, 41 months from diagnosis of MF, 43 months from the onset of transfusion dependence, 26 months from achieving transfusion independence, 33 months after stopping study medication, 21 months after stopping EPO, and 17 months after stopping deferasirox the $\mathrm{Hb}$ remained normal at $127 \mathrm{~g} / \mathrm{L}$ and SF was $493 \mathrm{ng} / \mathrm{mL}$.

Cytoreduction for thrombocytosis was given from February 2010 to June 2011 and was hydroxyurea and/or anagrelide with multiple dose adjustments to keep the PLT count < $1000 \times 10^{9} / \mathrm{L}$ while minimizing transfusion requirements. Cytoreduction was stopped as a requirement of the clinical trial. Hydroxyurea was resumed in January 2012 at a dose of $2 \mathrm{~g} /$ day and then decreased to 1.5 and $1 \mathrm{~g}$ in July 2012 and November 2013, respectively, to keep the platelet count less than 1000,400 , and $400 \times 10^{9} / \mathrm{L}$, respectively. She is currently receiving hydroxyurea $500 \mathrm{mg}$ once daily and the platelet count is $339 \times 10^{9} / \mathrm{L}$. In February 2015, a third analysis for the JAK-2 V617F mutation remained negative. The Hb, SF levels, transfusion requirements, and medications received over the patient's course are shown in Figure 1.

\section{Literature Review}

Characteristics of MDS patients reported to have achieved sustained TI after stopping ICT are summarized in Table 1. The median age at diagnosis of MDS or MPN of the seven reported cases was 61 (range 18-67) years, and five patients received deferoxamine (DFO) with two receiving DFX. The median duration of ICT was 20 (12-30) months and median time to RBC TI 20 (1.5-62) months (36 months for DFO and 3.25 months for DFX). The duration of RBC TI ranged from 3 to 36 months (five cases were reported as a range only).

\section{Discussion}

Transfusion independence following the initiation of iron chelation therapy, and while continuing to receive ICT, has been reported in both MDS and MPN. In larger series of lower IPSS risk MDS, erythroid response rates varied from $11 \%$ [36] to $45.6 \%$ [37]. A $12 \%$ rate of transfusion independence was seen in one study, and the probability of TI after adjusting for death and MDS progression was 2.6, 12.3 , and 15.5 at 6,9 , and 12 months, respectively [35]. In a study of 23 patients with MPN receiving deferasirox, 18 were evaluable for response. A persistent increase in $\mathrm{Hb}$ of greater than $1.5 \mathrm{~g} / \mathrm{dL}$ was observed in 5 patients, with 3 others 


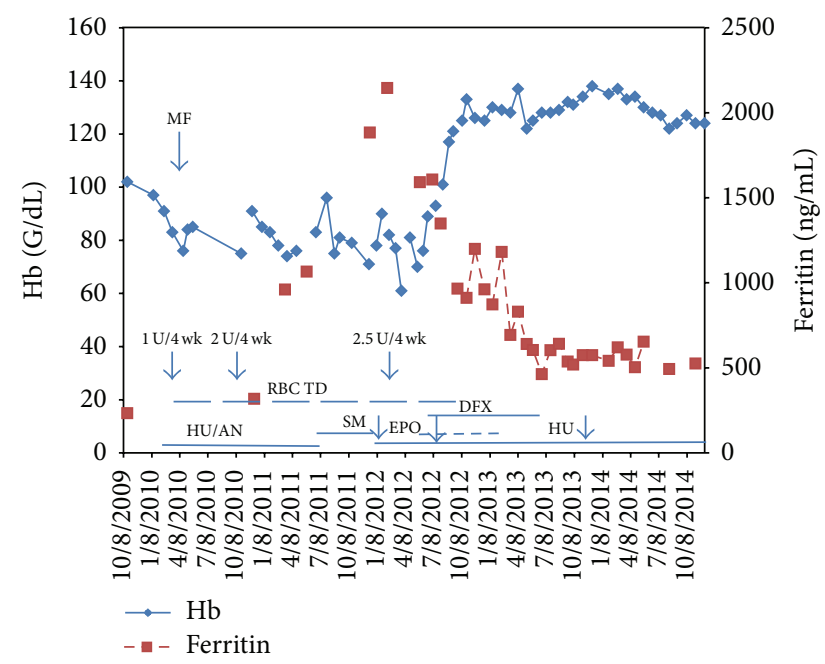

FIGURE 1: Clinical course of a patient with RARS-T evolved to myelofibrosis. Red blood cell transfusion dependence (RBC TD) started in 2010 and ended in August 2012, with number of RBC units (U) per 4 weeks (wk) indicated by the arrows. Hemoglobin $(\mathrm{Hb})$ levels are pretransfusion measurements during the period of $\mathrm{RBC}$ TD and are otherwise regular measurements. Hydroxyurea (HU) and/or anagrelide (AN) were given from February 2010 to June 2011 with multiple dose adjustments to keep the platelet count less than $1000 \times 10^{9} / \mathrm{L}$. These were stopped as a requirement of a clinical trial of pomalidomide versus placebo (study medication indicated by SM); SM was given from July 2011 to January 2012 and stopped for lack of response. HU was resumed at doses of 2, 1.5, and $1 \mathrm{~g} /$ day, respectively, as indicated by the arrows (left to right), to keep the platelet count less than 1000,400 , and $400 \times 10^{9} / \mathrm{L}$, respectively. Erythropoietin (EPO) was started in May 2012 at 40,000 U/wk and stopped in January 2013 because of a $\mathrm{Hb}$ of $130 \mathrm{~g} / \mathrm{dL}$. Deferasirox (DFX) was started in June 2012 (5 weeks after EPO) at a dose of $1500 \mathrm{mg} /$ day $(20 \mathrm{mg} / \mathrm{kg} / \mathrm{day})$. The patient's last RBC transfusion was on August 7, 2013.

becoming TI for an overall $\mathrm{HI}$ rate of $44 \%$ and TI rate of $17 \%$ [44]. Similarly, in 561 transfusion dependent patients with MF, 103 of whom received chelation, significantly lower rates of thrombocytopenia, pancytopenia, and emergency room visits were reported, adjusted incidence rate ratio of $0.54,0.53$, and 0.77 , respectively, $P<0.0001$ for all [43].

The mechanism of HI in MDS and MPN patients receiving chelation is a matter of active investigation. Though there appeared to be a greater reduction in serum ferritin levels in MDS patients with HI compared to those without, this difference did not reach statistical significance [31]. However, hematologic improvement has been reported with deferasirox [27, 31-33, 35-37, 41, 49-54], deferoxamine [2830,37 , and deferiprone [40], suggesting a class effect associated with iron reduction. This is supported by the observation of Jensen et al. that $\mathrm{HI}$ following deferoxamine was associated with greater reduction in liver iron concentration as measured by MRI [29]. Time to HI was a median of three (range 1-15) months with deferasirox and nine months with deferoxamine in one study [37], and TI was achieved after receiving deferoxamine for 18 to 26 months in another [29].
Whether $\mathrm{HI}$ is a result of reduction in organ and total body iron or from modulating other processes associated with iron overload remains to be clarified.

Mechanisms of HI with chelation that have been suggested include repression of the mTOR pathway, which reduced myeloid leukemia tumor volume in a preclinical model [55]. Deferasirox inhibits signaling via the nuclear transcription factor $\mathrm{NF} \kappa \mathrm{B}$; however this effect was not observed with deferoxamine or deferiprone, so it does not account for the HI observed with all three chelators [56]. In one study, suppression by deferasirox of helper T-type 1 cells and $\mathrm{T}$ regulatory cells was seen along with a shift toward a helper T-cell type 2 phenotype, indicating that alterations in immune surveillance may occur [57]. Also suggested are the following: a direct effect on the neoplastic clone or the bone marrow environment; promotion of iron release from stores allowing use by hemopoietic tissue; and an increase in endogenous EPO levels [58]. An attractive model is a reduction by chelation in oxidative stress, which is induced in states of iron overload by virtue of the ability of iron to transfer electrons, resulting in the formation of reactive oxygen species (ROS) [59]. In preclinical models, increased ferritin levels are associated with a reduction in erythroid colony formation in vitro $[60,61]$; iron overload induces apoptosis in erythroid precursors, and this correlates with the presence of ROS in CD34+ cells [62]. Similarly, measures of oxidative DNA damage are increased with transfusional iron overload and reduced following chelation with deferasirox for a period of three months; interestingly, this effect preceded an observed reduction in elevated serum ferritin levels [63]. Reductions in labile plasma iron (LPI), which is redox reactive, with chelation with deferasirox were demonstrated in two clinical studies [31,32]. Both showed a reduction in LPI into the normal range, in the US03 study by three months and in the EPIC trial by postadministration at baseline. In another analysis, intracellular ROS within erythrocytes was significantly suppressed following three months of chelation $(P<0.05)$ [64]. Taken together, demonstrated effects of oxidative stress on lipids, proteins, and nucleic acids $[55,63]$ could account for an increase in apoptosis observed with iron overload $[61,62]$ and relief of this could lead to HI and possibly to a survival benefit observed with chelation in noncontrolled analyses. To date, however, oxidative stress has not been definitively tied to clinical endpoints, possibly because it is reduced too quickly by chelation to accurately capture an association [31]. Measures of the longer lasting cellular results of oxidative stress might in future prove more revealing [63].

There has been little emphasis in the literature on outcomes in patients with marrow failure syndromes after stopping chelation following HI. In a case report of $\mathrm{HI}$ with deferasirox (DFX) in primary myelofibrosis (PMF), interruption of chelation at one month resulted in loss of HI which was regained when chelation was resumed [41]. A second patient with PMF attained TI after only 4 weeks of chelation with DFX, which was interrupted at 8 weeks for a decline in ferritin level. Following another 8 weeks, DFX was resumed for an increase in ferritin level; the patient remained TI for 6 months at the time of publication, including the 8 
TABLE 1: Characteristics of patients reported to have achieved sustained transfusion independence after stopping iron chelation therapy.

\begin{tabular}{|c|c|c|c|c|c|c|c|c|c|c|c|}
\hline Case & Age & $\begin{array}{c}\text { FAB or } \\
\text { WHO } \\
\text { diagnosis }\end{array}$ & $\begin{array}{c}\text { Karyotype at } \\
\text { diagnosis }\end{array}$ & $\begin{array}{l}\text { Risk } \\
\text { score }\end{array}$ & ICT & $\begin{array}{l}\text { Duration } \\
\text { of ICT }\end{array}$ & $\begin{array}{l}\text { Time to TI } \\
\text { (mo.) }\end{array}$ & $\begin{array}{l}\text { Duration } \\
\text { of TI (mo.) }\end{array}$ & $\begin{array}{l}\text { Duration of } \\
\text { TI after } \\
\text { stopping ICT } \\
\text { (mo.) }\end{array}$ & $\begin{array}{l}\text { Other } \\
\text { treatment }\end{array}$ & Reference \\
\hline 1 & 67 & RA & $\operatorname{del}(11)(\mathrm{q} 22 \mathrm{q} 24)$ & NR & $\mathrm{DFO}^{1}$ & 30 & 52 & NR & $3-36^{2}$ & $\begin{array}{c}\text { None } \\
\text { reported }\end{array}$ & [29] \\
\hline 2 & 46 & RA & Normal & NR & DFO & 25 & 20 & $24+$ & $3-36^{2}$ & $\begin{array}{l}\text { None } \\
\text { reported }\end{array}$ & [29] \\
\hline 3 & 41 & RA & Normal & NR & DFO & 20 & 36 & $20+$ & $3-36^{2}$ & $\begin{array}{l}\text { None } \\
\text { reported }\end{array}$ & [29] \\
\hline 4 & 18 & RAEB & Normal & NR & DFO & 20 & 20 & $6+$ & $3-36^{2}$ & $\begin{array}{l}\text { None } \\
\text { reported }\end{array}$ & [29] \\
\hline 5 & 65 & MDS & +8 & NR & DFO & 15 & 50 & NR & $3-36^{2}$ & Hydrea $^{3}$ & [29] \\
\hline 6 & 61 & $\mathrm{PMF}$ & NR & Int. $^{4}$ & DFX & 20 & 5 & $36+$ & $22+$ & None & {$[38]$} \\
\hline 7 & 63 & RARS-T & Normal & Low $^{5}$ & DFX & 12 & 1.5 & 22 & $12+$ & $\mathrm{EPO}^{6}$ & $\begin{array}{c}\text { Current } \\
\text { report }\end{array}$ \\
\hline
\end{tabular}

AML, acute myelogenous leukemia; DFO, deferoxamine; DFX, deferasirox; Int., intermediate; FAB, French American British; hydrea, hydroxyurea; IPSS, International Prognostic Scoring System; ICT, iron chelation therapy; MDS, myelodysplastic syndrome; mo., months; MPN, myeloproliferative neoplasm; PMF, primary myelofibrosis; RA, refractory anemia; RAEB, refractory anemia with excess blasts; MDS, myelodysplastic syndromes; MPN, myeloproliferative neoplasm; NR, not reported; PMF, primary myelofibrosis; RARS-T, refractory anemia with ring sideroblasts and thrombocytosis; TI, transfusion independence; WHO, World Health Organization; +, indicates ongoing TI.

${ }^{1}$ TI achieved 15 months after chelation was stopped. ${ }^{2}$ Duration of TI after stopping chelation for cases $1-5$ was reported as a range only. ${ }^{3}$ Hydroxyurea was given after stopping chelation due to progression to AML. ${ }^{4}$ Dupriez score (Dupriez et al., 1996 [45]). ${ }^{5}$ IPSS score for MDS (Greenberg et al., 1997 [1]). ${ }^{6}$ No response to EPO.

weeks off chelation [65]. In a third case, a PMF patient became TI with chelation after five months; deferasirox was stopped following twelve months of chelation, and TI was maintained two years later [38]. In a report of seven MDS patients with HI following deferoxamine, TI was not the focus of the study; however five patients became TI after treatment for 18 to 26 months. The duration of TI in this study was a minimum of 3 months and up to 36 months at the time of publication. Our patient received twelve months of chelation before it was stopped and durable HI was observed. Angelucci et al. [35] demonstrated a time-dependence in TI rates during the first 12 months of chelation with DFX, but the optimal duration of chelation to maximize the incidence of TI remains to be clarified. Also unclear topics for future investigation are as follows: which characteristics of MDS and MPN patients predict HI with chelation; and which MDS and MPN subtypes are more likely to respond.

We cannot rule out a clonal switch in our patient, as no follow-up marrow was done, and analysis for the JAK2 V617F mutation remained negative throughout her course. However, clonal evolution generally results in worsening of the hematologic picture, and there are hints of this occurring in our patient before treatment with deferasirox, as indicated by the increasing transfusion requirement and less exuberantly increased platelet count, which may indicate progression of fibrosis beyond the proliferative phase. In the Jensen study [29], it appeared that patients received supportive care alone beyond ICT. The PMF patient reported by di Tucci et al. [38] received no other treatment beyond ICT. Our patient, though she received EPO, did not respond to EPO alone and maintained HI and TI 21 months after EPO was stopped. Though HI with EPO would not be surprising, to our knowledge, sustained TI long term after stopping EPO has not been reported. We also cannot rule out a delayed response to study medication, presuming she was randomized to receive pomalidomide, though this would have occurred more than a year from starting, and more than 6 months from stopping, and response is ongoing over 3.5 and 3 years from starting and stopping. In trials of pomalidomide for myelofibrosis, the reported median time to response was 1.6 months and response duration was 6.7 months, with one patient with transfusion independence having a response of 15 months [66]. In a second study, the median anemia response duration was 16 months, and in a third the range was 3.2-16.9 months, all considerably shorter than the response duration of our patient $[67,68]$. To our knowledge, there is no information available as to expected response of thrombocytosis to pomalidomide, nor is there specific information on pomalidomide activity in RARS-T. There is, however, a case report of RARS-T treated with lenalidomide which resulted in resolution of splenomegaly but severe and prolonged pancytopenia [69]. EPO alone, while expected to improve RBC transfusion requirements in some patients, would not be expected to improve thrombocytosis, as was seen in this patient. An improvement in thrombocytosis was also observed in a PMF patient achieving TI following DFX [65]. Taken together, these observations indicate that some patients may achieve durable TI with ICT alone. Whether the $\mathrm{HI}$ is additive or synergistic with other therapies expected to induce HI remains to be defined [70].

In summary, our patient's achievement of durable TI even following discontinuation of iron chelation therapy improved prognostic scores predicting overall survival. In two other reports of this phenomenon, sustained TI was not a focus of 
one and potential mechanisms of HI were not discussed at any length $[29,38]$. The current report highlights that durable transfusion independence may be achieved in some patients with acquired anemias following reduction of iron overload, suggesting a favorable impact on bone marrow failure in some patients with acquired anemias. The course of these patients may inform future analyses and clinical trial design.

\section{Conflict of Interests}

Heather A. Leitch has received honoraria from Novartis Corporation and is a member of the Exjade Speaker's Bureau. Harpreet Kochhar and Chantal S. Leger have no conflict of interests to disclose.

\section{Acknowledgments}

Harpreet Kochhar was supported by a Summer Studentship from the Center for Blood Research, University of British Columbia. Chantal S. Leger and Heather A. Leitch designed the report. Harpreet Kochhar and Heather A. Leitch wrote the paper. Chantal S. Leger and Heather A. Leitch critically reviewed the paper.

\section{References}

[1] P. Greenberg, C. Cox, M. M. LeBeau et al., "International scoring system for evaluating prognosis in myelodysplastic syndromes," Blood, vol. 89, no. 6, pp. 2079-2088, 1997.

[2] P. L. Greenberg, H. Tuechler, J. Schanz et al., "Revised international prognostic scoring system for myelodysplastic syndromes," Blood, vol. 120, no. 12, pp. 2454-2465, 2012.

[3] R. S. Komrokji, M. Corrales-Yepez, N. Al Ali et al., "Validation of the MD Anderson Prognostic Risk Model for patients with myelodysplastic syndrome," Cancer, vol. 118, no. 10, pp. 26592664, 2012.

[4] L. Malcovati, U. Germing, A. Kuendgen et al., “Time-dependent prognostic scoring system for predicting survival and leukemic evolution in myelodysplastic syndromes," Journal of Clinical Oncology, vol. 25, no. 23, pp. 3503-3510, 2007.

[5] J. Schanz, H. Tüchler, F. Solé et al., "New comprehensive cytogenetic scoring system for primary myelodysplastic syndromes (MDS) and oligoblastic acute myeloid leukemia after MDS derived from an international database merge," Journal of Clinical Oncology, vol. 30, no. 8, pp. 820-829, 2012.

[6] R. Buckstein, S. Alibhai, A. Lam et al., "Transfusion dependence and low hemoglobin have the greatest impact on quality of life (QOL) in MDS patients-a tertiary care cross sectional and longitudinal study," Blood, vol. 114, no. 22, pp. 986a-987a, 2009.

[7] L. de Swart, A. Smith, P. Fenaux et al., "Disease-management of low- and intermediate-1 risk myelodysplastic syndromes: report on 800 newly diagnosed MDS patients from the European LeukemiaNet MDS registry," Blood, vol. 116, no. 21, pp. 12011202, 2010, [abstract 2917].

[8] L. Malcovati, M. G. Della Porta, and M. Cazzola, "Predicting survival and leukemic evolution in patients with myelodysplastic syndrome," Haematologica, vol. 91, no. 12, pp. 1588-1590, 2006.

[9] L. Malcovati, M. G. D. Porta, C. Pascutto et al., "Prognostic factors and life expectancy in myelodysplastic syndromes classified according to WHO criteria: a basis for clinical decision making," Journal of Clinical Oncology, vol. 23, no. 30, pp. 7594-7603, 2005.

[10] G. Sanz, B. Nomdedeu, E. Such et al., "Independent impact of iron overload and transfusion dependency on survival and leukemic evolution in patients with myelodysplastic syndrome," Blood, vol. 112, no. 11, pp. 238a-239a, 2008.

[11] D. K. Hiwase, M. M. Kutyna, R. Chhetri et al., "Transfusion dependency is associated with inferior survival even in very low and low risk IPSS-R patients," Blood, vol. 122, no. 1, 2013, abstract 1518.

[12] L. de Swart, A. Smith, P. Fenaux et al., "Early mortality in 1000 newly diagnosed MDS patients with low- and intermediate1 risk MDS in the European leukemianet MDS (EUMDS) registry," Blood, vol. 2012, no. 21, abstract 3830, 2012.

[13] H. A. Leitch, "Improving clinical outcome in patients with myelodysplastic syndrome and iron overload using iron chelation therapy," Leukemia Research, vol. 31, no. 3, pp. S7-S9, 2007.

[14] H. A. Leitch, C. S. Leger, T. A. Goodman et al., "Improved survival in patients with myelodysplastic syndrome receiving iron chelation therapy," Clinical Leukemia, vol. 2, no. 3, pp. 205211, 2008.

[15] J. Neukirchen, F. Fox, A. Kündgen et al., "Improved survival in MDS patients receiving iron chelation therapy-a matched pair analysis of 188 patients from the Düsseldorf MDS registry," Leukemia Research, vol. 36, no. 8, pp. 1067-1070, 2012.

[16] C. Rose, S. Brechignac, D. Vassilief et al., "Does iron chelation therapy improve survival in regularly transfused lower risk MDS patients? A multicenter study by the GFM,' Leukemia Research, vol. 34, no. 7, pp. 864-870, 2010.

[17] R. S. Komrokji, N. H. Al Ali, E. Padron, J. E. Lancet, and A. F. List, "Impact of iron chelation therapy on overall survival and AML transformation in lower risk MDS patients treated at the Moffitt Cancer Center," Blood, vol. 118, no. 21, pp. 1196a-1197a, 2011, abstract 2776 .

[18] F. Remacha, B. Arrizabalaga, C. Del Canizo, G. Sanz, and A. Villegas, "Iron overload and chelation therapy patterns in low risk myelodysplastic syndromes with transfusion requirements. A cross sectional observational national study in Spain (iron study)," Haematologica, vol. 93, supplement 1, p. 278a, 2008.

[19] R. M. Lyons, B. J. Marek, S. Sharma et al., "24-month analysis of the impact of chelation on clinical outcomes in a 600 patient registry of lower-risk MDS patients," Blood, vol. 118, no. 21, p. 1207-8a, 2011, abstract 2800.

[20] A. M. Zeidan, F. Hendrick, E. Friedmann et al., "Deferasirox is associated with reduced mortality risk in a medicare population with myelodysplastic syndromes," Blood, vol. 120, no. 21, 2012, ASH Annual Meeting Abstracts: Abstract 426.

[21] M. Delforge, D. Selleslag, A. Triffet et al., "Retrospective analysis on the impact of iron chelation therapy on survival and leukemia progression in transfusion dependent MDS patients in Belgium," Haematologica, vol. 97, supplement 1, p. 371, 2012, EHA Annual Meeting Abstracts: Abstract 898.

[22] A. Pardanani, C. Finke, R. A. Abdelrahman, T. L. Lasho, and A. Tefferi, "Associations and prognostic interactions between circulating levels of hepcidin, ferritin and inflammatory cytokines in primary myelofibrosis," American Journal of Hematology, vol. 88, no. 4, pp. 312-316, 2013.

[23] A. D. Pardanani, T. L. Lasho, C. Finke, R. A. Abdelrahman, C. A. Hanson, and A. Tefferi, "Serum ferritin level at referral provides independent prognostic information for overall survival in primary myelofibrosis," Blood, vol. 122, no. 21, abstract 2824, 2013. 
[24] H. A. Leitch, J. M. Chase, T. A. Goodman et al., "Improved survival in red blood cell transfusion dependent patients with primary myelofibrosis (PMF) receiving iron chelation therapy," Hematological Oncology, vol. 28, no. 1, pp. 40-48, 2010.

[25] B. D. Cheson, J. M. Bennett, H. Kantarjian et al., "Report of an international working group to standardize response criteria for myelodysplastic syndromes," Blood, vol. 96, no. 12, pp. 36713674, 2000.

[26] B. D. Cheson, P. L. Greenberg, J. M. Bennett et al., "Clinical application and proposal for modification of the International Working Group (IWG) response criteria in myelodysplasia," Blood, vol. 108, no. 2, pp. 419-425, 2006.

[27] M. A. Badawi, L. M. Vickars, J. M. Chase, and H. A. Leitch, "Red blood cell transfusion independence following the initiation of iron chelation therapy in myelodysplastic syndrome," Advances in Hematology, vol. 2010, Article ID 164045, 5 pages, 2010.

[28] J. del Río Garma, C. F. Lago, and F. J. B. Fonrodona, "Desferrioxamine in the treatment of myelodysplastic syndromes," Haematologica, vol. 82, no. 5, pp. 639-640, 1997.

[29] P. D. Jensen, L. Heickendorff, B. Pedersen et al., "The effect of iron chelation on haemopoiesis in MDS patients with transfusional iron overload," British Journal of Haematology, vol. 94, no. 2, pp. 288-299, 1996.

[30] P. D. Jensen, I. M. Jensen, and J. Ellegaard, “Desferrioxamine treatment reduces blood transfusion requirements in patients with myelodysplastic syndrome," British Journal of Haematology, vol. 80, no. 1, pp. 121-124, 1992.

[31] N. Gattermann, C. Finelli, M. D. Porta et al., "Hematologic responses to deferasirox therapy in transfusion-dependent patients with myelodysplastic syndromes," Haematologica, vol. 97, no. 9, pp. 1364-1371, 2012.

[32] A. F. List, M. R. Baer, D. P. Steensma et al., "Deferasirox reduces serum ferritin and labile plasma iron in RBC transfusiondependent patients with myelodysplastic syndrome," Journal of Clinical Oncology, vol. 30, no. 17, pp. 2134-2139, 2012.

[33] A. Molteni, M. Riva, A. Pellizzari et al., "Hematological improvement during iron-chelation therapy in myelodysplastic syndromes: the experience of the 'Rete Ematologica Lombarda," Leukemia Research, vol. 37, no. 10, pp. 1233-1240, 2013.

[34] J.-W. Cheong, H.-J. Kim, K.-H. Lee et al., "Deferasirox improves hematologic and hepatic function with effective reduction of serum ferritin and liver iron concentration in transfusional iron overload patients with myelodysplastic syndrome or aplastic anemia," Transfusion, vol. 54, no. 6, pp. 1542-1551, 2014.

[35] E. Angelucci, V. Santini, A. A. di Tucci et al., "Deferasirox for transfusion-dependent patients with myelodysplastic syndromes: safety, efficacy, and beyond (GIMEMA MDS0306 Trial)," European Journal of Haematology, vol. 92, no. 6, pp. 527536, 2014.

[36] F. Nolte, B. Höchsmann, A. Giagounidis et al., "Results from a 1-year, open-label, single arm, multi-center trial evaluating the efficacy and safety of oral Deferasirox in patients diagnosed with low and int-1 risk myelodysplastic syndrome (MDS) and transfusion-dependent iron overload," Annals of Hematology, vol. 92, no. 2, pp. 191-198, 2013.

[37] D. Cilloni, E. Messa, L. Biale et al., "High rate of erythroid response during iron chelation therapy in a cohort of 105 patients affected by hematologic malignancies with transfusional iron overload: an Italian multicenter retrospective study," Blood, vol. 118, no. 2, abstract 611, 2011.

[38] A. A. di Tucci, R. Murru, D. Alberti, B. Rabault, S. Deplano, and E. Angelucci, "Correction of anemia in a transfusion-dependent patient with primary myelofibrosis receiving iron chelation therapy with deferasirox (Exjade, ICL670)," European Journal of Haematology, vol. 78, no. 6, pp. 540-542, 2007.

[39] J. H. Marsh, M. Hundert, and P. Schulman, "Deferoxamineinduced restoration of haematopoiesis in myelofibrosis secondary to myelodysplasia," British Journal of Haematology, vol. 76, no. 1, pp. 148-149, 1990.

[40] M. E. P. Smeets, G. Vreugdenhil, and R. S. G. Holdrinet, "Improvement of erythropoiesis during treatment with deferiprone in a patient with myelofibrosis and transfusional hemosiderosis," The American Journal of Hematology, vol. 51, no. 3, pp. 243-244, 1996.

[41] E. Messa, D. Cilloni, F. Messa, F. Arruga, A. Roetto, and G. Saglio, "Deferasirox treatment improved the hemoglobin level and decreased transfusion requirements in four patients with the myelodysplastic syndrome and primary myelofibrosis," Acta Haematologica, vol. 120, no. 2, pp. 70-74, 2008.

[42] H. Tesch and C. Ihling, "Loss of transfusion dependency following deferasirox treatment of iron overload in a woman with myelofibrosis and spherocytosis-a case report," Onkologie, vol. 36, no. 4, pp. 205-208, 2013.

[43] F. Vekeman, W. Y. Cheng, M. Sasane et al., "Medical complications in patients with myelofibrosis by frequency of blood transfusion and iron chelation therapy," Blood, vol. 122, no. 21, abstract 2964, 2013.

[44] R. Latagliata, R. Montagna, R. Porrini et al., "Deferasirox in the treatment of iron overload during myeloproliferative neoplasms (MPN)," Blood, vol. 122, no. 21, abstract 1594, 2013.

[45] B. Dupriez, P. Morel, J. L. Demory et al., "Prognostic factors in agnogenic myeloid metaplasia: a report on 195 cases with a new scoring system," Blood, vol. 88, no. 3, pp. 1013-1018, 1996.

[46] J. W. Vardiman, J. Thiele, D. A. Arber et al., "The 2008 revision of the World Health Organization (WHO) classification of myeloid neoplasms and acute leukemia: rationale and important changes," Blood, vol. 114, no. 5, pp. 937-951, 2009.

[47] N. Gangat, D. Caramazza, R. Vaidya et al., "DIPSS plus: a refined dynamic international prognostic scoring system for primary myelofibrosis that incorporates prognostic information from karyotype, platelet count, and transfusion status," Journal of Clinical Oncology, vol. 29, no. 4, pp. 392-397, 2011.

[48] M. G. Della Porta, L. Malcovati, E. Boveri et al., "Clinical relevance of bone marrow fibrosis and CD34-positive cell clusters in primary mvelodvsplastic syndromes," Journal of Clinical Oncology, vol. 27, no. 5, pp. 754-762, 2009.

[49] S. Capalbo, G. Spinosa, M. G. Franzese, and G. Palumbo, "Early deferasirox treatment in a patient with myelodysplastic syndrome results in a long-term reduction in transfusion requirements," Acta Haematologica, vol. 121, no. 1, pp. 19-20, 2009.

[50] H. Okabe, T. Suzuki, T. Omori et al., "Hematopoietic recovery after administration of deferasirox for transfusional iron overload in a case of myelodysplastic syndrome," The Japanese Journal of Clinical Hematology, Case Reports Review, vol. 50, no. 11, pp. 1626-1629, 2009.

[51] E. N. Oliva, F. Ronco, A. Marino, C. Alati, G. Praticò, and F. Nobile, "Iron chelation therapy associated with improvement of hematopoiesis in transfusion-dependent patients," Transfusion, vol. 50, no. 7, pp. 1568-1570, 2010.

[52] R. Guariglia, M. C. Martorelli, O. Villani et al., "Positive effects on hematopoiesis in patients with myelodysplastic syndrome receiving deferasirox as oral iron chelation therapy: a brief review," Leukemia Research, vol. 35, no. 5, pp. 566-570, 2011. 
[53] M. Breccia, G. Loglisci, A. Salaroli, L. Cannella, M. Santopietro, and G. Alimena, "Deferasirox treatment interruption in a transfusion-requiring myelodysplastic patient led to loss of erythroid response," Acta Haematologica, vol. 124, no. 1, pp. 4648, 2010.

[54] T. Nishiuchi, Y. Okutani, T. Fujita, K. Yoshida, H. Ohnishi, and R. Haba, "Effect of iron chelator deferasirox on chronic anemia and thrombocytopenia in a transfusion-dependent patient with myelodysplastic syndrome," International Journal of Hematology, vol. 91, no. 2, pp. 333-335, 2010.

[55] J. H. Ohyashiki, C. Kobayashi, R. Hamamura, S. Okabe, T. Tauchi, and K. Ohyashiki, "The oral iron chelator deferasirox represses signaling through the mTOR in myeloid leukemia cells by enhancing expression of REDD1," Cancer Science, vol. 100, no. 5, pp. 970-977, 2009.

[56] E. Messa, S. Carturan, C. Maffè et al., "Deferasirox is a powerful NF- $\kappa b$ inhibitor in myelodysplastic cells and in leukemia cell lines acting independently from cell iron deprivation by chelation and reactive oxygen species scavenging," Haematologica, vol. 95, no. 8, pp. 1308-1316, 2010.

[57] S. Opat, N. Mifsud, A. Banerjee et al., "P-240 Haematopoietic improvement following iron chelation may result from deferasirox-induced restoration of T cell immune surveillance," Leukemia Research, vol. 37, supplement 1, p. S131, 2013.

[58] X. Ren, K. L. Dorrington, P. H. Maxwell, and P. A. Robbins, "Effects of desferrioxamine on serum erythropoietin and ventilatory sensitivity to hypoxia in humans," Journal of Applied Physiology, vol. 89, no. 2, pp. 680-686, 2000.

[59] N. Gattermann and E. A. Rachmilewitz, "Iron overload in MDS-pathophysiology, diagnosis, and complications," Annals of Hematology, vol. 90, no. 1, pp. 1-10, 2011.

[60] J. Hartmann, F. Braulke, U. Sinzig et al., "Iron overload impairs proliferation of erythroid progenitors cells (BFU-E) from patients with myelodysplastic syndromes," Leukemia Research, vol. 37, no. 3, pp. 327-332, 2013.

[61] K. Taoka, K. Kumano, F. Nakamura et al., "The effect of iron overload and chelation on erythroid differentiation," International Journal of Hematology, vol. 95, no. 2, pp. 149-159, 2012.

[62] L. S. A. Chan, R. Buckstein, M. D. Reis et al., "Iron overload and haematopoiesis in MDS: does blood transfusion promote progression to AML?” Blood, vol. 112, no. 11, p. 928a, 2008.

[63] M. Kobune, S. Kikuchi, S. Iyama et al., "Iron chelation therapy could rapidly reduce oxidative DNA damage in CD34+ hematopoietic cells before decrease of serum ferritin level," Blood, vol. 122, no. 21, abstract 959, 2013.

[64] H. Ghoti, J. Amer, A. Winder, E. Rachmilewitz, and E. Fibach, "Oxidative stress in red blood cells, platelets and polymorphonuclear leukocytes from patients with myelodysplastic syndrome," European Journal of Haematology, vol. 79, no. 6, pp. 463-467, 2007.

[65] D. C. Lisette, B. Enrico, A. Eleonora, G. Riccardo, M. Manlio, and R. Omar, "Mayor erythropoietic response after deferasirox treatment in a transfusion-dependent anemic patient with primary myelofibrosis," Case Reports in Hematology, vol. 2013, Article ID 520712, 4 pages, 2013.

[66] N. Daver, A. Shastri, T. Kadia et al., "Modest activity of pomalidomide in patients with myelofibrosis and significant anemia," Leukemia Research, vol. 37, no. 11, pp. 1440-1444, 2013.

[67] K. H. Begna, A. Pardanani, R. Mesa et al., "Long-term outcome of pomalidomide therapy in myelofibrosis," The American Journal of Hematology, vol. 87, no. 1, pp. 66-68, 2012.
[68] A. Tefferi, S. Verstovsek, G. Barosi et al., "Pomalidomide is active in the treatment of anemia associated with myelofibrosis," Journal of Clinical Oncology, vol. 27, no. 27, pp. 4563-4569, 2009.

[69] G. Taylor, D. Culligan, and M. A. Vickers, "Refractory anemia with ring sideroblasts associated with marked thrombocytosis complicated by massive splenomegaly treated with lenalidomide resulting in resolution of splenomegaly but severe and prolonged pancytopenia," Case Reports in Hematology, vol. 2013, Article ID 718480, 3 pages, 2013.

[70] Combination Study of Deferasirox and Erythropoietin in Patients with Low- and Int-1-risk Myelodysplastic Syndrome, 2013, http://clinicaltrials.gov/show/NCT01868477. 


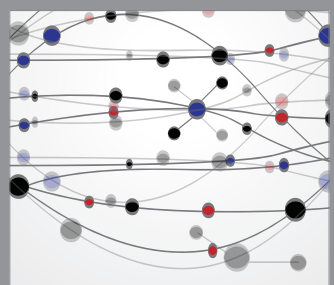

The Scientific World Journal
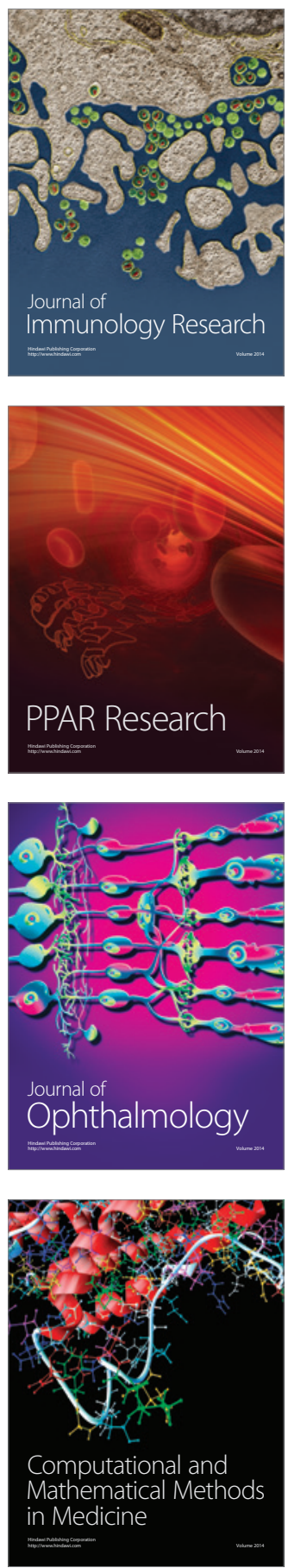

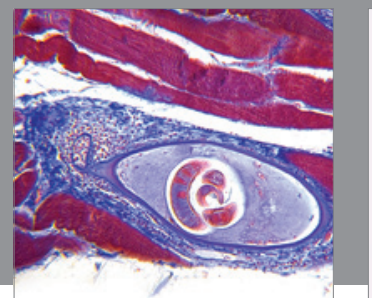

Gastroenterology

Research and Practice
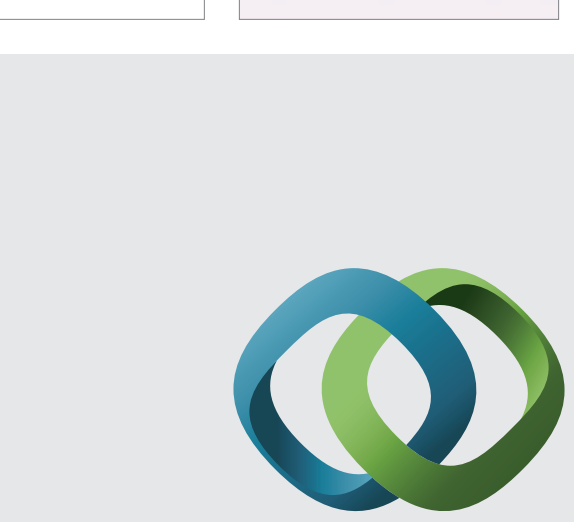

\section{Hindawi}

Submit your manuscripts at

http://www.hindawi.com
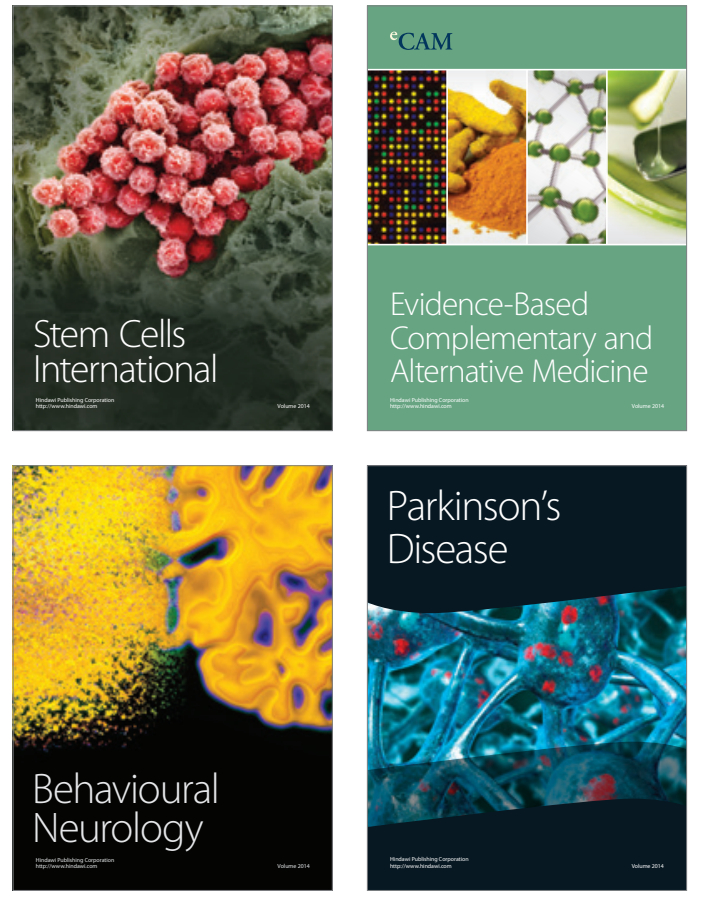
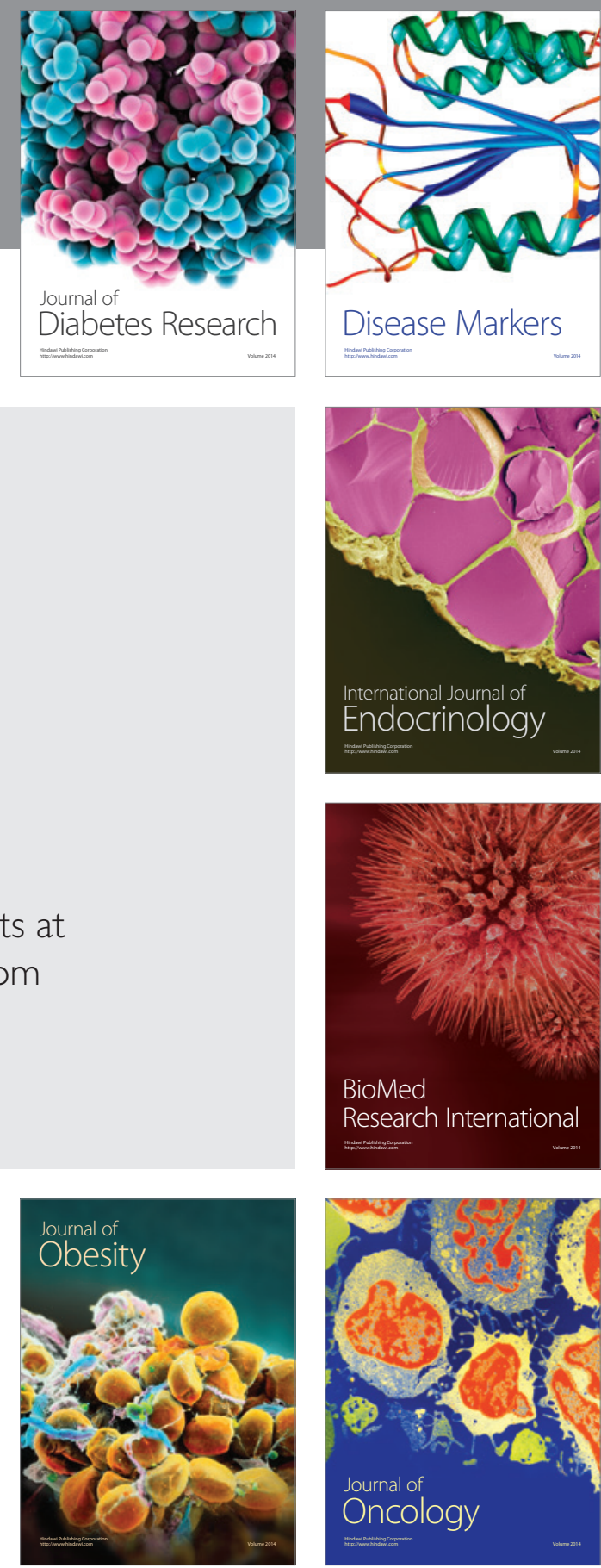

Disease Markers
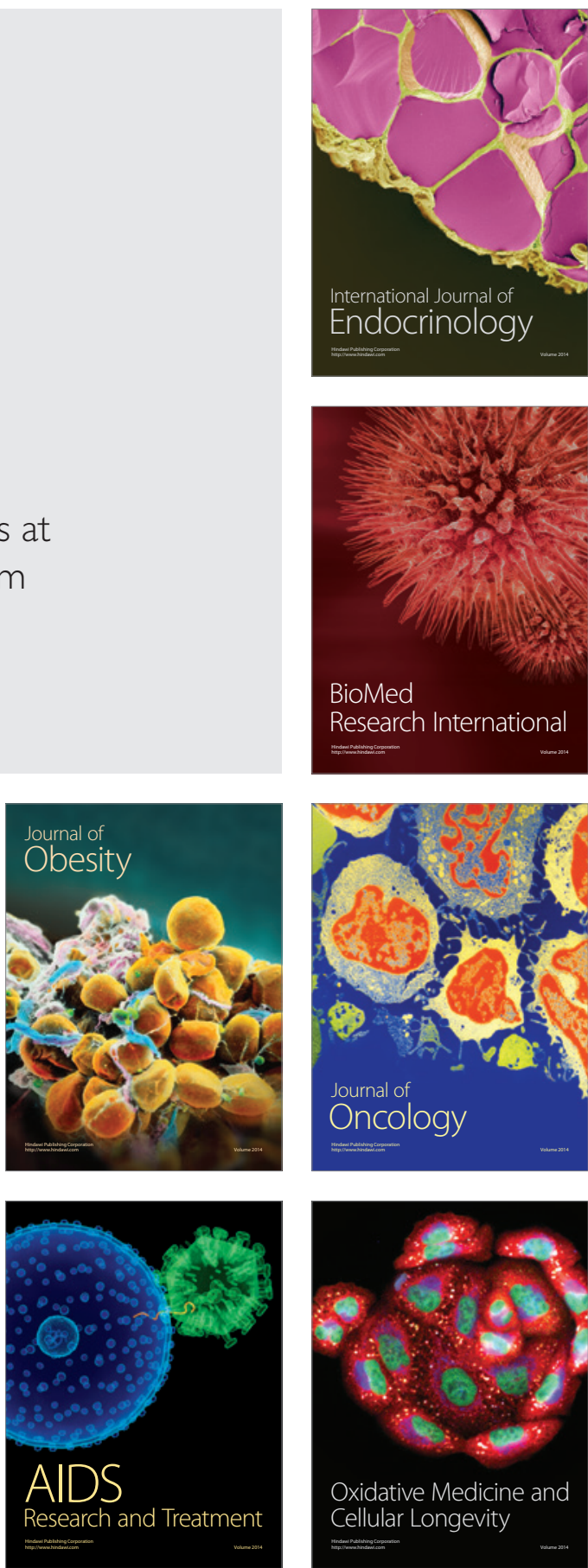